\title{
Thermal behaviour and toxic emissions of various timbers in cone calorimeter tests
}

\author{
D. Tsatsoulas ${ }^{1}$, H. N. Phylaktou ${ }^{2} \&$ G. Andrews ${ }^{2}$ \\ ${ }^{1}$ Greek Fire Service, Thessaloniki, Greece \\ ${ }^{2}$ ERRI, University of Leeds, UK
}

\begin{abstract}
This work investigated the thermal behaviour and toxic emissions of timber products common in industrial buildings in Northern Greece. Eight species of wood typically employed in floors, ceilings, shelves, pallets, packing cases, scaffolding, furniture etc., were selected for experimental investigation. The samples were subjected to constant incident heat fluxes of 35, 50,65 and $80 \mathrm{kWm}^{-2}$ in a cone calorimeter linked to a FTIR analyzer.

Test results presented in this paper, cover the following characteristics: (i) Time to ignition; (ii) Heat Release Rate (HRR); (iii) Time to reach peak HRR; (iv) Average (300s) HRR; (v) Mass Loss Rate; (vi) Effective heat of combustion $(\mathrm{MJ} / \mathrm{kg}$ ); (vii) Smoke production and toxic species emissions. In general, a relatively fast ignition was observed from 75 to $100 \mathrm{~s}$ at $35 \mathrm{~kW} / \mathrm{m}^{2}$, which dropped to $15 \mathrm{~s}$ (mean value of all samples) at $80 \mathrm{~kW} / \mathrm{m}^{2}$. An exception to this were some composite types of wood with a facing finishing layer, i.e., MDF or chipboard faced with melamine or maple, especially at $35 \mathrm{~kW} / \mathrm{m}^{2}$, which demonstrated an increased ignition resistance (MDF and chipboard by a factor of 1.5 to 2). Among the various samples, 'no significant' differences were observed in terms of peak HRR at all irradiance levels. "Significant" acrolein peak values were measured for all samples. Samples with a facing layer (melamine in particular), which are known to have chemical flame retardation reached higher peak values of $\mathrm{CO}, \mathrm{HCN}$ and $\mathrm{NH}_{3}$ during combustion.
\end{abstract}

Keywords: wood, cone calorimeter, Heat Release Rate, ignition, emissions.

\section{Introduction}

Wood has many good properties as a material. It is heavily used for construction and building because of its ease of processing, physical and mechanical 
properties, aesthetic, environmental and health aspects [1]. Wood is also used in many applications for purposes such as surface lining material, furniture, flooring, roof, shelves, pallets, wooden scaffolding for both offshore and onshore, packing cases $[1,2]$. All these surfaces may add significantly to the fire loading of a compartment, aid the spread of flame and advance the onset of flashover.

There are three stages of heat action on wood that are involved in the combustion of wood. These are [1,3], Preliminary (flameless) stage; Main (flame) stage; Final (flameless) stage. The preliminary stage involves the dehydration and the release of liquid and volatile compounds, while heating the wood to its decomposition temperature $[1,3]$. The main flame stage includes the ignition of thermal decomposition products, flame spread by combustible gases and an increase in heat release and mass loss rates [1,3]. This is the active process of decomposition. The final stage includes the slow burning of the residue and ashing of the remaining matter, however this stage is not often reached $[1,3]$. In particular, the toxicity resulting from the thermal decomposition of wood and cellulosic substances is complex because of the wide variety of types of wood smoke [4]. The composition and the concentration of the individual constituents depend on such factors as the fire exposures, the oxygen and moisture present, the species of wood, any treatments or finishes that may have been applied, and other considerations [4].

There is a large amount of work in the literature regarding different aspects of the burning characteristics of wood. This has included work on the ignition and burning behaviour of wood. Alen et al. [5] examine the thermochemical behaviour of the different constituents of wood, and state that the pyrolysis of wood is dominated by the behaviour of its two main fractions, Carbohydrates (cellulose and hemi-celluloses) on the one hand and lignin substances on the other. Hao [6] presents a general account of how various physical properties affect the burning behaviour of wood and finds that with the variation of different types of wood. Therefore, the different chemical compositions, lead to differing HRRs; with higher lignin content the HRR decreases and a higher moisture content will significantly decrease the HRR. Horrocks and Price [7] state that the ignition of wood occurs between $300-400^{\circ} \mathrm{C}$, although the exact temperature depends on the origin of the wood, finding that species with higher lignin concentration tend to have a higher ignition temperature. Various works stated that for all wooden materials, an initial peak is seen following ignition and again another is seen before burn out [3, 8]. Finally, Drysdale [3] states that the burning of wood is a much more complex process than that of synthetic polymers, whether charring or non-charring.

In this work we will be looking into the burning characteristics of different commonly used timbers/wood products in Northern Greek industry.

\section{Experimental}

The apparatus used was a standard cone calorimeter manufactured in accordance to ISO 5660 (1993) and ASTM E1354 (1992) supplied by Fire Testing Technology Ltd. The tests were carried out in accordance with the test procedure 
of ISO 5660 except in regards to the time at which the test was terminated. All tests were carried out in the horizontal orientation at heat fluxes of 35, 50, 65 and $80 \mathrm{~kW} / \mathrm{m}^{-2}$. An edge frame was used in accordance with the standard resulting in a specimen surface area of $0.0088 \mathrm{~m}^{2}$ exposed to the radiant source. The instrument was calibrated at the start of each day. The cabinet door was kept closed for the duration of the test to ensure that drafts from the surroundings did not affect results.

A TEMET GASMET CR-Series portable FTIR analyzer was connected to the cone calorimeter at $35,50,65 \mathrm{~kW} / \mathrm{m}^{2}$. This has a multi-pass, gold-coated sample cell with a $2 \mathrm{~m}$ path length and volume of 0.221 . A liquid nitrogen cooled MCT detector was used that scans 10 spectra per second and several scans are used to produce a time-averaged spectrum. The whole detector cell was heated as more than adequate to resolve the time dependent toxic gas production in the present fires, which lasted for typically 10 minutes. The Temet FTIR gives a 2ppm resolution with an accuracy of $2 \%$ and a precision well as the sample line, pump and filter. The instrument was calibrated by the manufacturers for the 60 species using reference gas concentrations. The FTIR was calibrated for all the significant species that were present in the sample The only calibration necessary prior to the test was to zero the instrument on nitrogen. The response time of the instrument is $5 \mathrm{~s}$ to reliability resolve all 51 species that it can measure (only 23 of these are toxic and only the most toxic of these will be reported in the present results).

\subsection{Sample preparation}

Substrates were $100 \mathrm{~mm}$ square and thickness varied from $19 \mathrm{~mm}$ to $22 \mathrm{~mm}$ and were supplied from a local timber merchant. The sample was cut from larger sheets of $4.5 \mathrm{~m} \times 3.5 \mathrm{~m}$. All specimens for test were prepared in advance and allowed to "temper" at room temperature and ambient humidity for a minimum of 24 hours. Time duration of each test was in general $600 \mathrm{sec}$. The reason for that is that present work is interested in examining the development of fires on wooden samples during the early stage of fire development, and for a period of time up to $10 \mathrm{~min}$, which, in real fire conditions, covers the time needed for the evacuation of the industrial plant by its staff, the potential intervention of the fire-safety staff of the plant, and the arrival of the fire department to extinguish the fire.

\subsection{Experimental fires configuration}

The selection of the heat flux is a very important factor when undertaking cone calorimeter tests [9]. The current tests were carried out at heat fluxes of 35, 50, $65,80 \mathrm{~kW} / \mathrm{m}^{2}$, to represent a possible range of heat fluxes to be encountered in a developing industrial fire. The aim was to expose all samples to the same radiation in order to be able to compare them. Fewer tests have been performed at $80 \mathrm{~kW} / \mathrm{m}^{2}$ because of technical difficulties which did not allow further experiments to be performed at such a large value of irradiance. Based on the above, eight species of wood which constitute common applications in different forms i.e., floor, ceiling, shelves, pallets, packing cases, scaffolding, furniture 
Table 1: $\quad$ Virgin sample tests.

\begin{tabular}{|c|c|c|}
\hline Virgin Samples & Heat flux & No of tests \\
\hline Chipboard & $35,50,65,80 \mathrm{~kW} / \mathrm{m}^{2}$ & 12 tests \\
\hline MDF & $35,50,65,80 \mathrm{~kW} / \mathrm{m}^{2}$ & 12 tests \\
\hline Chipboard covered by maple $(2-3 \mathrm{~mm})$ & $35,50,65 \mathrm{~kW} / \mathrm{m}^{2}$ & 9 tests \\
\hline MDF covered by maple $(2-3 \mathrm{~mm})$ & $35,50,65,80 \mathrm{~kW} / \mathrm{m}^{2}$ & 12 tests \\
\hline Chipboard covered by melamine $(2-3 \mathrm{~mm})$ & $35,50,65,80 \mathrm{~kW} / \mathrm{m}^{2}$ & 12 tests \\
\hline MDF covered by melamine $(2-3 \mathrm{~mm})$ & $35,50,65 \mathrm{~kW} / \mathrm{m}^{2}$ & 9 tests \\
\hline European Pine & $35,50,65,80 \mathrm{~kW} / \mathrm{m}^{2}$ & 12 tests \\
\hline Blockboard & $35,50,65,80 \mathrm{~kW} / \mathrm{m}^{2}$ & 12 tests \\
\hline Total virgin tests & & $\mathbf{9 0}$ tests \\
\hline
\end{tabular}

The abbreviations are: cb 'chipboard', cb/maple 'chipboard covered by maple', cb/melamine 'chipboard covered by melamine', MDF/maple 'MDF covered by maple', $\mathrm{MDF} /$ melamine 'MDF covered by melamine', Bb 'Blockboard'.

etc., were chosen for experimental investigation [2]. In total 90 tests (see Table 1) have been performed in total at various irradiances, in order to determine various flammability characteristics of a range of virgin wood species.

Five typical types of wood i.e. pine, MDF, MDF faced by maple, MDF faced by melamine $(2-3 \mathrm{~mm})$, blockboard were chosen as representative to examine with FTIR analyzer that was connected to the cone calorimeter. Chipboard was not tested, since its experimental processing showed that its behavior is not particularly different, comparing with the other wood type of similar morphology and composition i.e. MDF. Toxic yields of main toxic gases were assessed for better comparison of toxic species of different fire loads [2]. The main reason that the above samples were chosen was to assess the concentration of toxic gasses in fires of typical wooden samples.

\subsection{Thermal behaviour - experimental results}

Fire development results cover: i. Time to ignition(s); ii. HRR $\left(\mathrm{kW} / \mathrm{m}^{2}\right)$; iii. Time to reach peak HRR (s) iv. Average (300s) HRR; v. Mass Loss Rate (g/s); vi. Effective heat of combustion $(\mathrm{MJ} / \mathrm{kg})$. All tests were fairly repeatable in terms of the tig and HRR values i.e., 2-8\% Std. dev. (expresses the standard deviation as a percentage of the average value). Greater deviation was measured for the types of wood that were composite in nature, i.e. blockboard, MDF faced by melamine, or maple, where there might have been slight variations in the surface density and the samples construction. Experimental results represent the mean of a minimum of three tests.

\subsubsection{Time to ignition}

The time to ignition, tig, has been used as the primary method of comparing the flammability of samples. Figure 1 presents the time to ignition for eight wood 
samples, as chosen according to the criteria mentioned before. At $35 \mathrm{~kW} / \mathrm{m}^{2}$ heat flux, the largest value is seen for chipboard faced by melamine (tig $=156 \mathrm{sec}$ ) and MDF faced by melamine (tign $=145 \mathrm{sec}$ ), which are due to the flame retarding action of melamine $\left(\mathrm{C}_{3} \mathrm{H}_{6} \mathrm{~N}_{6}\right)$ as coating material [10] i.e., during its thermal decomposition releasing an acid which esterifies hydroxil groups of carbonizing substance to form a thermally unstable ester in the presence of a catalyst which delays the ignition of the sample.

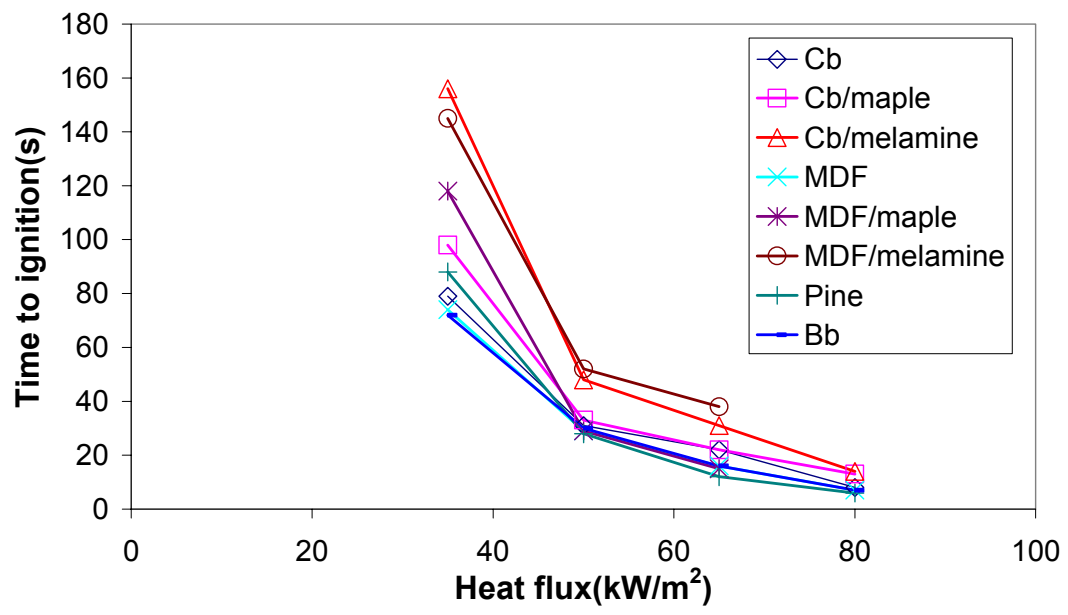

Figure 1: $\quad$ Time to ignition vs irradiances for different wood species.

Some other noticeably larger values are seen for the cases of the following types of wood; chipboard faced by maple and MDF faced by maple, with values 98sec and $118 \mathrm{sec}$, respectively, which are due to the higher- density hardwood of maple, as coating material which contains more di-methoxy phenolic groups in comparison with the other soft and composite in nature species [12]. These dimethoxy derivatives might be more effective in stabilizing free radicals during the initial irradiance exposure, delaying thus the time to ignition. The rest values for the other types of wood range from 72 to $88 \mathrm{sec}$, i.e., without any significant variation among them. It appears that organic improvers, e.g., wax, resin etc included into the glue that contained into the mass of the composite in nature samples i.e. MDF, chipboard, blockboard contribute to the slightly faster ignition of these samples.

However as the heat flux levels increase the ignition resistance decreases significantly and the differences between the time of ignition of different types of wood as well as the protective effect of melamine and maple is diminished. Fewer tests were performed at $80 \mathrm{~kW} / \mathrm{m}^{2}$, because of the technical difficulties that occurred.

Work by others

The average value of $34 \mathrm{~s}$ at $50 \mathrm{~kW} / \mathrm{m}^{2}$ for chipboard is similar to those found in the literature $[11,13]$, where values of $34 \mathrm{~s}$ and $33 \mathrm{~s}$ are reported. Under the same 
testing conditions at $50 \mathrm{~kW} / \mathrm{m}^{2}$, for blockboard and pine, a value of $26 \mathrm{sec}$ and $28 \mathrm{sec}$ were found in the literature $[11,14]$, which are similar to the average value found in this work, i.e., $24 \mathrm{sec}$ and $28 \mathrm{sec}$, respectively. In addition, almost converging values are seen in the results referring to chipboard (at 35, 50, 65, $80 \mathrm{~kW} / \mathrm{m}^{2}$ ), blockboard (at $50 \mathrm{~kW} / \mathrm{m}^{2}$ ) and are reported in McCreadie PhD work [15] $\mathrm{n}$ the tests performed at the same lab at the University of Leeds.

\subsubsection{Heat Release Rate}

Examples of the HRR curves obtained with the different samples at $35 \mathrm{~kW} / \mathrm{m}^{2}$ irradiance are shown in Figure 2. The ignition time as reported in the previous section is related to the sudden increase in the HRR signal and this is indicated (as an example) in Figure 2 for chipboard faced by melamine.

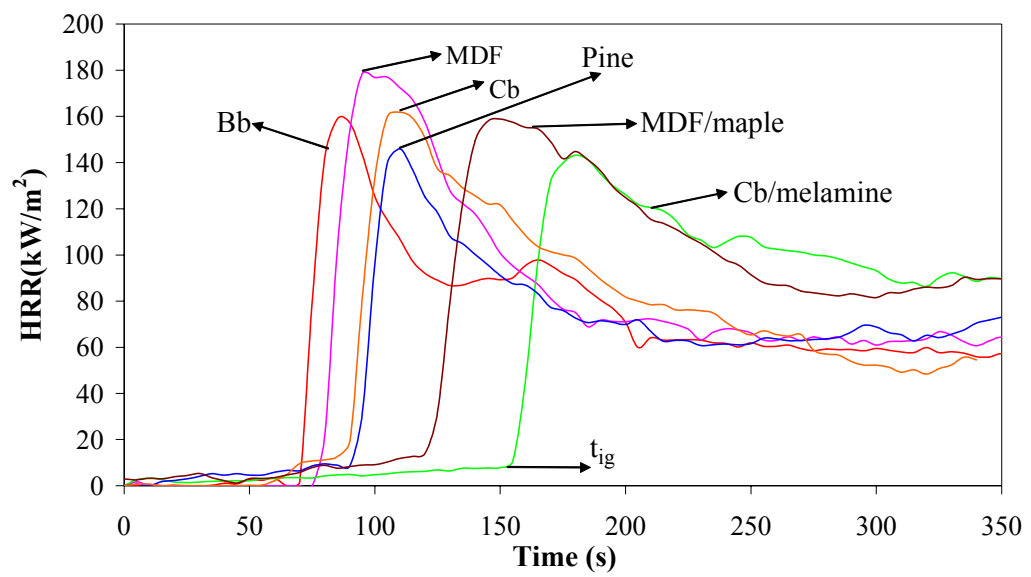

Figure 2: $\quad \operatorname{HRR}\left(\mathrm{kW} / \mathrm{m}^{2}\right)$ vs time for MDF, chipboard, MDF faced by maple, chipboard faced by melamine, blockboard, pine, at $35 \mathrm{kw} / \mathrm{m}^{2}$.

As shown for all samples, ignition was followed by a peak in the HRR. The HRR then decreased to an almost constant rate. The curves in Figure 2 are truncated at $350 \mathrm{~s}$ as there was nothing remarkable in the rest of the signal. The reader is reminded that monitoring was carried out for the first $600 \mathrm{~s}$. Some tests were allowed to proceed to burnout in these cases a second peak associated with the burnout was observed in accordance with other work in the Literature as discussed before. The peak discussed here and throughout the Thesis is the first peak occurring after ignition rather than the burnout peak for the reasons specified before.

As the radiative flux was increased the time to ignition is reduced and the differences in the initial part of the HRR curves were diminished. There also appeared to be a general increase in the max HRR as irradiance increased and this is further analysed below.

As can be seen from Figure 3, peak HRR values $\left(\mathrm{kW} / \mathrm{m}^{2}\right)$ increase as irradiances increase for all wood species. At $35 \mathrm{~kW} / \mathrm{m}^{2}$ heat flux peak HRR values, range from $178 \mathrm{~kW} / \mathrm{m}^{2}$ for $\mathrm{MDF}$ to $143 \mathrm{~kW} / \mathrm{m}^{2}$ for pine. At $50 \mathrm{~kW} / \mathrm{m}^{2}$ heat flux, the smallest peak values among the different wood species are once 
again seen in pine i.e., $150 \mathrm{~kW} / \mathrm{m}^{2}$, while the largest value is once again the value for MDF, i.e. $209 \mathrm{~kW} / \mathrm{m}^{2}$. At $65 \mathrm{~kW} / \mathrm{m}^{2}$ heat flux, almost same behavior is observed, where the smallest value is the value for pine, $163 \mathrm{~kW} / \mathrm{m}^{2}$ and the largest value is the one for MDF, $269 \mathrm{~kW} / \mathrm{m}^{2}$. At $80 \mathrm{~kW} / \mathrm{m}^{2}$, the smallest value is again the one for pine, $197 \mathrm{~kW} / \mathrm{m}^{2}$ and the largest value is again the one for MDF, $303 \mathrm{~kW} / \mathrm{m}^{2}$. These quite small fluctuations in the peak HRR values seem to be due to the different physical properties of different wood species, i.e. pine (soft wood) demonstrated slightly lower peak values due to its homogeneous composition, compared to samples covered with melamine or maple. On the other hand, chipboard and MDF species, due to their composite structure with small-glued particles or fibres, give slightly higher peak values than other samples. The use of organic improvers, e.g., wax, resin etc., lead to an increase in the heat release rate (HRR) in these cases.

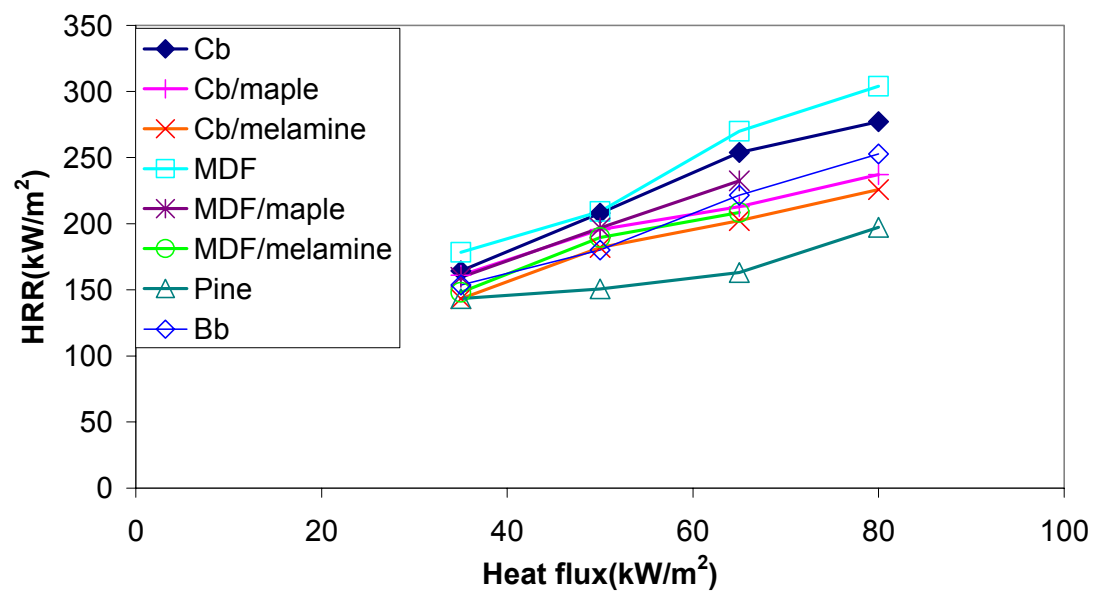

Figure 3: $\quad$ Peak HRR values vs irradiances for eight (8) wood species chosen.

Substrates covered by melamine or maple, extend the ignition delay as mentioned before, and seem to reduce the peak HRR values for MDF and chipboard against fire conditions.

\section{Work by others}

Grexa and Lubke [13] report a similar peak of $200 \mathrm{~kW} / \mathrm{m}^{2}$ for chipboard tested at $50 \mathrm{~kW} / \mathrm{m}^{2}$. McCreadie [15] reports similar results under same testing conditions for chipboard (at $35,50,65,80 \mathrm{~kW} / \mathrm{m}^{2}$ ) and blockboard (at $50 \mathrm{~kW} / \mathrm{m}^{2}$ ) which provides confidence in the present results. White and Dietenberger [14] report $154 \mathrm{~kW} / \mathrm{m}^{2}$ peak H.R.R. for pine at $50 \mathrm{~kW} / \mathrm{m}^{2}$ which is near with the relevant peak value of the present work. No data was found in literature under the same conditions for chipboard, MDF covered by maple or melamine to compare with data in the present work. Further complications in getting comparable data are the variations in the composition of the natural woods and in the composite in nature woods. 


\subsubsection{Time to reach peak HRR}

In this work the time to reach the peak HRR is taken as the time from the first exposure to the irradiance (shutter opening time) to the time of peak HRR (some researchers measure the time to peak HRR from the time of ignition). The time to reach peak HRR is an important parameter when assessing the fire performance of a material and it has been proposed as a parameter than can be used as an indication of a material's propensity (when used as wall lining) to cause flashover when used in conjunction with other data [15].

It was generally observed that the time to reach the peak HRR decreased as irradiance increased (see Figure 4). Longer time was needed for melamine and maple covered species, whereas no remarkable differences were seen among the other wood species.

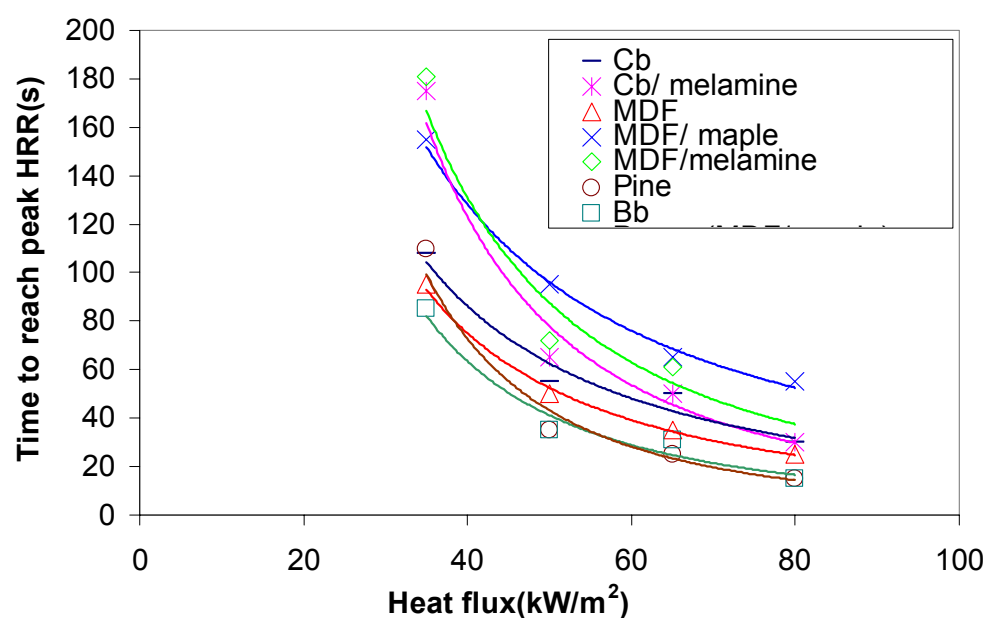

Figure 4: Average time $(\mathrm{sec})$ to reach peak HRR $\left(\mathrm{kW} / \mathrm{m}^{2}\right)$ for virgin samples.

\subsubsection{Heat Release Rate averaged over 300s after ignition}

Figure 5 shows the mean HRR taken over the first 300s after ignition for virgin woods as recommended [3, 9]. This increased as the irradiance increased. Higher average values occurred for composite in nature samples for the reasons mentioned above.

\subsubsection{Effective heat of combustion (EHC)}

The mass loss rate $(\mathrm{g} / \mathrm{s})$ increased with heat flux in agreement with the heat release rate results as was expected. They follow the same trend as for the HRR data and the peaks on the MLR curve tend to coincide with the peaks on the HRR curve. The EHC (MJ/kg) calculated from HRR and MLR data measured in the cone calorimeter is termed 'effective' as combustion may be incomplete (i.e. the production of soot and CO) and the heat losses to the surroundings are not measured. Therefore the value determined is less that the net heat of combustion that is determined in bomb calorimetry [9]. Average values of EHC determined for a duration of $300 \mathrm{sec}$ after ignition for all samples (see Figure 6). 


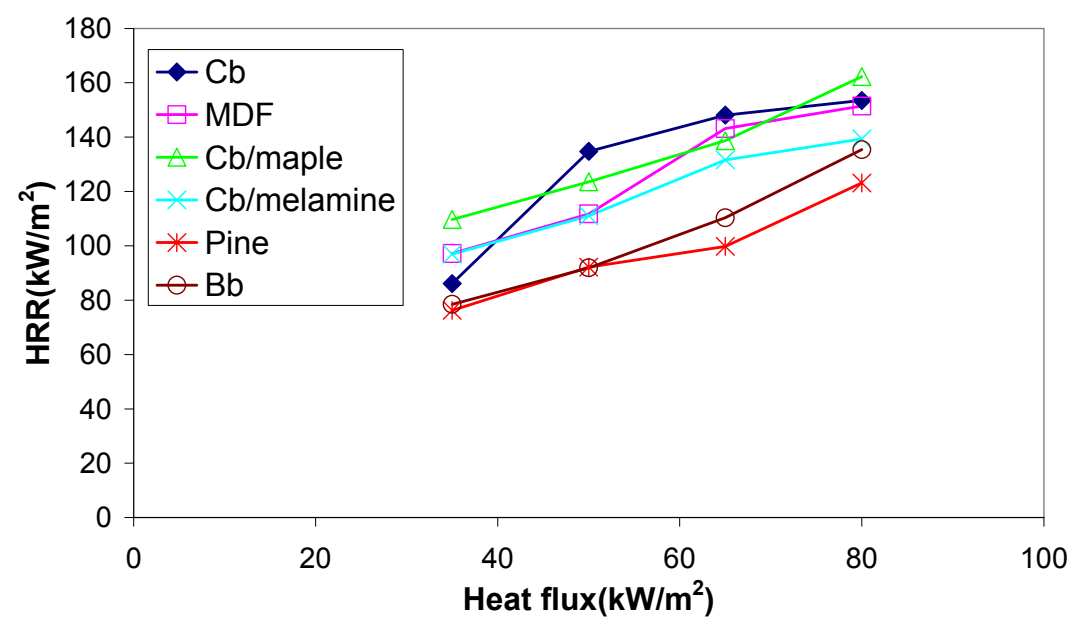

Figure 5: Average 300s HRR $\left(\mathrm{kW} / \mathrm{m}^{2}\right)$ vs heat flux $\left(\mathrm{kW} / \mathrm{m}^{2}\right)$ for virgin samples.

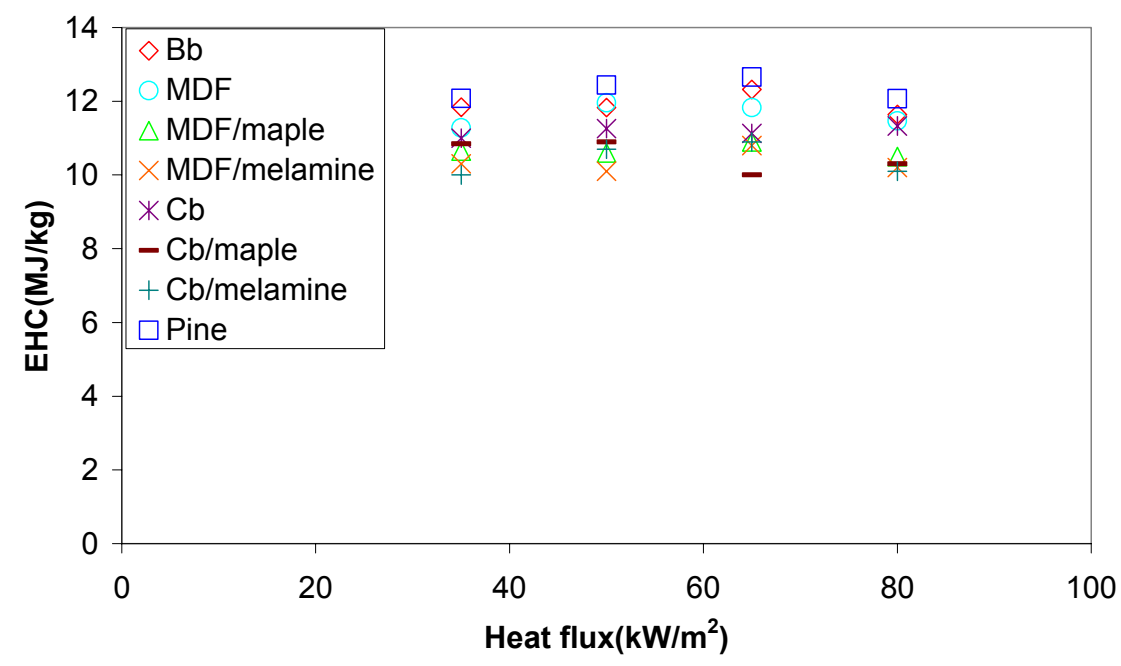

Figure 6: Average EHC over 300s after ignition.

EHC values of virgin samples are independent of heat flux demonstrating that the EHC is an intrinsic material property. This is in agreement with the work by McCready [15]. Lower values were measured for samples with a facing layer (melamine or maple). 


\subsection{Emissions - experimental results}

\subsubsection{Smoke production}

To compare the smoke production of the samples, the smoke extinction coefficient (Ks) was used which is a measure of the attenuation of light by the smoke.

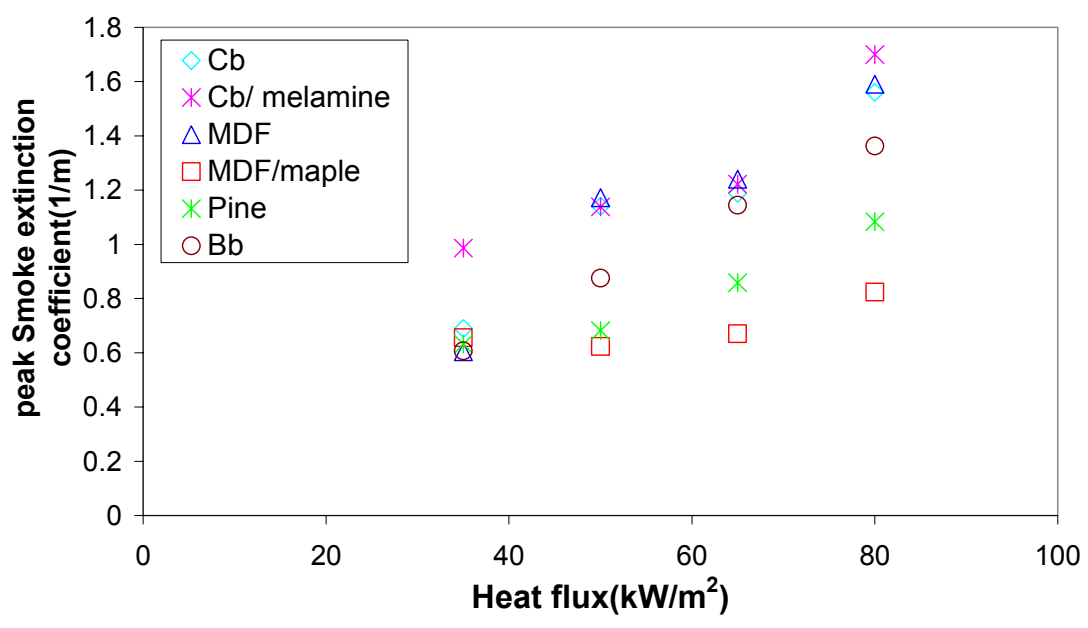

Figure 7: Peak smoke Extinction Coefficient for uncoated wood species.

In most irradiances chipboard covered with melamine produced highest smoke concentration peaks. In general samples composite in nature gave higher smoke peaks than solid pine with the exception of maple covered MDF which produced lower smoke concentrations than pine at higher irradiances. This may be attributed to the influence of the maple cover layer as discussed earlier. As shown in Figure 7 generally the peak $\mathrm{K}_{\mathrm{S}}$ increases as the irradiances increase.

\subsubsection{Toxicity}

In this section we present the findings from the cone calorimeter/FTIR tests using five different types of wood.

2.4.2.1 CO emissions. Figure 8 compares peak $\mathrm{CO}$ emissions (ppm) of all types of timber tested. In general, peak values tended to slightly increase with irradiance levels. The peak values were generally low, i.e., less than $90 \mathrm{ppm}$, for all samples without facing, i.e., blockboard, pine and MDF, at all irradiance levels examined here. Increased values, higher than $200 \mathrm{ppm}$ (15 min exposure COSHH limit) [17], were measured for MDF faced with maple and MDF faced with melamine at all irradiance levels (see Figure 8). Therefore, it seems that samples with a facing layer reached higher peak values of $\mathrm{CO}$ during combustion. This could be attributed to the coupling effect between substrate MDF (which contains organic improvers, wax, resin etc) and glued facings 
i.e. melamine, maple, etc. Also, these materials (melamine in particular) are known to have a chemical flame retardation effect which would reduce the combustion rate by interrupting the reactions. A by-product is higher $\mathrm{CO}$ concentrations because of unfinished combustion. The lower $\mathrm{CO}$ emission peak values were observed with the pine samples, presumably due to their natural texture.

Figure 9 compares peak mass $\mathrm{CO}$ emissions $(\mathrm{g} / \mathrm{kg})$ for various wooden samples. Peak CO $(\mathrm{g} / \mathrm{kg})$ has a tendency to decrease with irradiance levels, and this is attributed to the increase of combustion efficiency as irradiance increased.

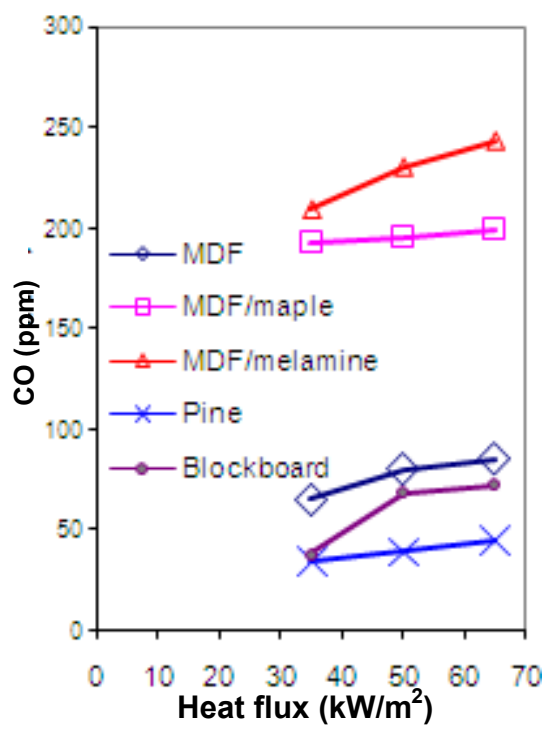

Figure 8: Peak CO emissions (ppm) vs irradiances for the five wood species chosen.

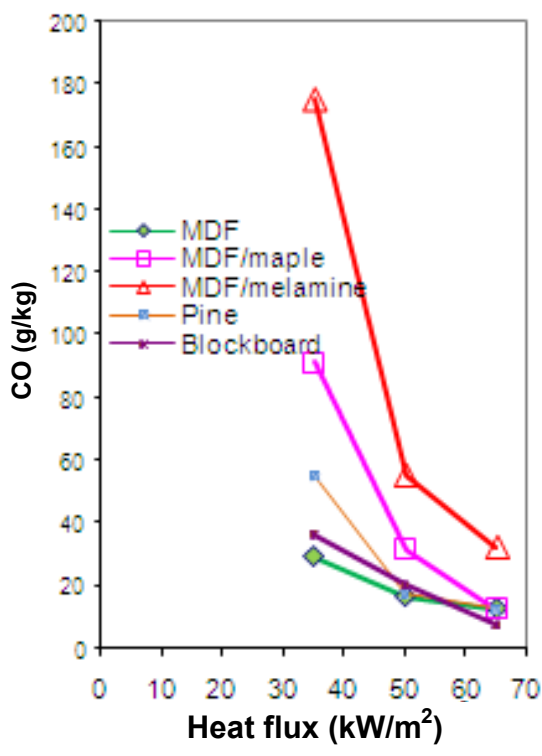

Figure 9: Peak $\mathrm{CO}$ emissions $(\mathrm{g} / \mathrm{kg})$ vs irradiances for the five wood species chosen.

2.4.2.2 $\mathrm{HCN}$ and $\mathrm{NH}_{3}$ emissions. For all virgin samples at all irradiances examined, 'no significant' $\mathrm{HCN}$ and $\mathrm{NH}_{3}$ concentrations were released. The exception to this rule was MDF faced by melamine where, due to the nitrogen content of melamine, higher $\mathrm{HCN}$ and $\mathrm{NH}_{3}$ concentrations were released during burning, especially, at 50 and $65 \mathrm{~kW} / \mathrm{m}^{2}$. These concentrations exist only for short period probably only during combustion of thin layer of melamine (2$3 \mathrm{~mm}$ ). Peak values of $\mathrm{HCN}$ and $\mathrm{NH}_{3}$ emissions did not present any clear trend with increasing heat flux.

2.4.2.3 Acrolein emissions. The acrolein emission signals were 'messy' showing a 'discontinuous' behavior, oscillated between 0-25 ppm (see Figure 10). The STEL limit for acrolein is reported as $0.3 \mathrm{ppm}$ while the $5 \mathrm{~min}$ 
tenability limit is given as 2ppm [16] [17]. "Significant" peak values $>>0.3 p p m$ are measured (15min exposure limit as specified in STEL) for all samples. A tendency toward a reduction in peak values is observed with an increase in irradiance for untreated samples. The reason for this was the slower fire development at low irradiances which favors partial oxidation of released hydrocarbons to aldehydes, such as acrolein.

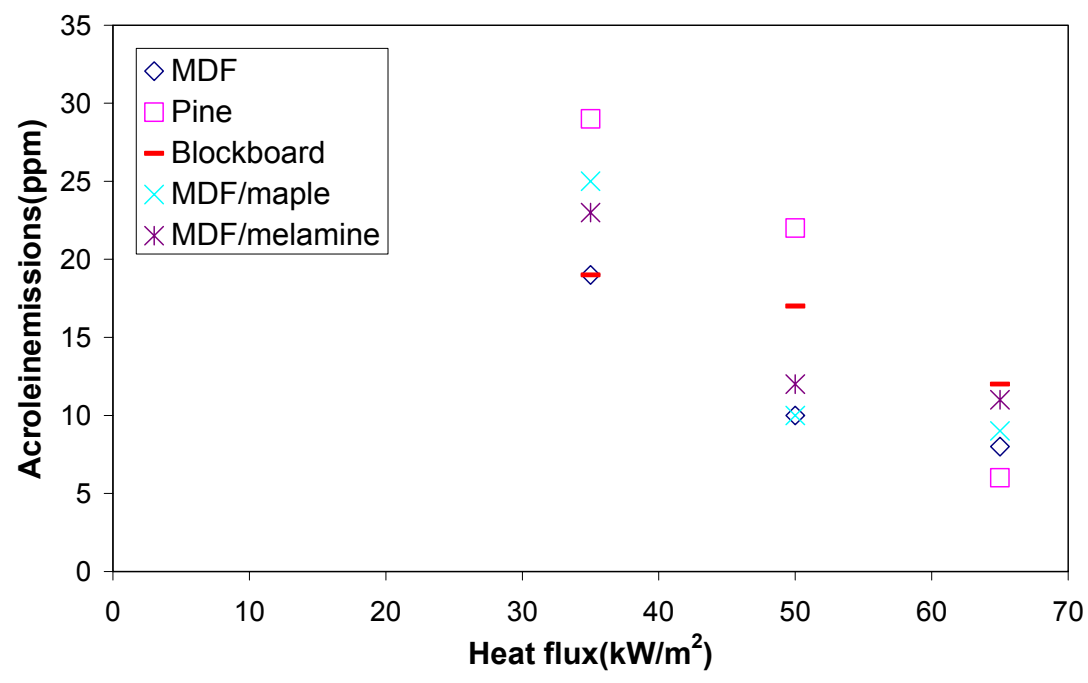

Figure 10: Peak acrolein emissions (ppm) for wood species.

2.4.2.4 Other toxic gases. There was 'no significant' values of $\mathrm{NO}$ and $\mathrm{NO}_{2}$. The exception to this rule was MDF faced by melamine where, due to the nitrogen content of melamine, higher $\mathrm{NO}$ and $\mathrm{NO}_{2}$ concentrations were released during burning, especially, at 50 and $65 \mathrm{~kW} / \mathrm{m}^{2}$. These concentrations of $\mathrm{NO}$ and $\mathrm{NO}_{2}$ exist only for short period probably only during combustion of thin layer of melamine $(2-3 \mathrm{~mm})$. Insignificant values of $\mathrm{HCI}$, $\mathrm{HF} \mathrm{NH}_{3}$, Toluene, were measured .Their peak and averaged values were much lower than $15 \mathrm{~min}$ COSHH exposure limits [17]

\section{Conclusions}

Eight (8) types of wood, the most widely used in Greek industries, were chosen for experimental testing in a cone calorimeter (small-scale).

'No significant' differences were observed in terms of HRR values. Some slightly lower HRR peak values $\left(\mathrm{kW} / \mathrm{m}^{2}\right)$ were noted for homogeneous (pine) compared with composite in nature samples (e.g., MDF, chipboard). Substrates covered by melamine or maple, seem slightly to reduce the peak HRR values for MDF and chipboard against fire conditions. 
At low irradiance (i.e., $35 \mathrm{~kW} / \mathrm{m}^{2}$ ), facing types of timber, e.g., $\mathrm{MDF}, \mathrm{Cb}$, with melamine or maple increases significantly the ignition resistance of MDF and $\mathrm{Cb}$ by a factor of 1.5 to 2 , due to the flame retarding properties of melamine and maple.

"Significant" acrolein peak values are measured for all samples. Samples with a facing layer (melamine in particular), which are known to have a chemical flame retardation reached higher peak values of $\mathrm{CO}, \mathrm{HCN}$ and $\mathrm{NH}_{3}$ during combustion.

\section{Future work/suggestions}

Experiment investigation of the application of flame retardants (using the latest technology: intumescent or nanocomposites) on wooden surfaces as a possible method:

1. to 'improve' thermal behavior of wood (reducing HRR, extend time to ignition)

2. to reduce toxic emissions of wooden surfaces.

The flame retardant application on wooden surfaces located close to ignition sources is possible to be a safe and effective approach in reducing fire losses in industries.

\section{References}

[1] Spearpoint, M.J., and Quintiere, J.G. 'Predicting the piloted ignition of wood in the cone calorimeter using an integral model-Effect of species, grain orientation and heat flux'. Fire safety journal, vol. 36, pp. 391-415, 2001.

[2] Dimitrios Tsatsoulas. 'Industrial fires in Northern Greece. The influence of flame retardant on Timber Fires'. Ph.D. Thesis, Leeds (UK) 2008.

[3] D. Drysdale, 'An introduction to fire dynamics', $2^{\text {nd }}$ edition. Wiley (1999).

[4] Julie L, Neviaser and Richard G. Gann, 'Evaluation of toxic potency values for smoke from products and materials', Fire Technology 40:22, pp. 177-199, 2004.

[5] Alen R, Kuoppala E, Oesch P. 'Formation of the main degradation compund groups from wood and its components during pyrolysis'. Journal of Analytical and Applied Pyrolysis,vol 36, pp. 137-148,1996.

[6] Hao C.Tran. 'Experimental data on wood materials'. Heat release in fires', pp. 357-372, 1992.

[7] Horrocks A.R., Price D. 'Fire retardant materials', pp.7, 10, 293-305, 325327, 2001.

[8] Sprearpoint, M.J., and Quintiere, J.G. 'Predicting the burning of wood using an integral model-Combustion and flame', vol. 123, pp.308-324, 2000.

[9] BSI DD246. 'Recommendations for the use of cone calorimeter', British standards institute, 1999. 
[10] Maria Wladyka-Przydylak and Ryszard Kozlowski. 'The thermal characteristics of different in-tumescent coatings'. Fire and materials 23, pp.33-43, 1999.

[11] B. Karlssson, 'Models for calculation flame spread on wall linings materials and the resulting heat release rate in a room'. Fire Safety Journal 23(1994), pp. 365-386.

[12] Errin L, Anderson, Zenon Pawlak, Noel L. Owen, and William C. Feist. 'Infrared studies of wood weathering'. Part II: Hardwoods'. Department Forest Chemistry. Brigham Young University and Forest Products Laboratory, Service.

[13] Grexa O, Lubke H. 'Flammability parameters of wood tested on a cone calorimeter'. Polymer degradation and stability',vol.74, pp.427-432,2001.

[14] Robert H. White and Mark A. Dietenberger, 'Cone Calorimeter evaluation of wood products', Fifteenth Annual BCC Conference on Flame Retardancy, 2004.

[15] Ryan McCready. 'The Flammability of coatings'. PhD Thesis, University of Leeds, 2004.

[16] Andrews, et al., 'FTIR investigations of toxic gases in air starved enclosed fires' 8th International Symposium, pp.1035-1046, Association for Fire Safety, 2005.

[17] Control of Substances Hazardous to Health Regulations 2002 (as amended), HSE Books, UK Health and Safety Executive. 